\title{
Efficacy and safety of daptomycin for skin and soft tissue infections: a systematic review with trial sequential analysis
}

This article was published in the following Dove Press journal:

Therapeutics and Clinical Risk Management

22 September 2016

Number of times this article has been viewed

\author{
Chao Liu',* \\ Zhi Mao',* \\ Mengmeng Yang' \\ Hongjun Kang' \\ Hui Liu' \\ Liang Pan' \\ Jie $\mathrm{Hu}^{\prime}$ \\ Jun Luo ${ }^{2}$ \\ Feihu Zhou' \\ 'Department of Surgical Intensive \\ Care Unit, Chinese People's \\ Liberation Army General Hospital, \\ Beijing, ${ }^{2}$ Department of Surgical \\ Intensive Care Unit, Xuanhan \\ People's Hospital, Sichuan, People's \\ Republic of China \\ *These authors contributed equally \\ to this work
}

Correspondence: Feihu Zhou

Department of Critical Care Medicine,

Chinese People's Liberation Army

General Hospital, 28 Fu-Xing Road,

Beijing 100853, People's

Republic of China

Tel +861066938148

Fax +86 I0 882I 9862

Email feihuzhou30I@।26.com
Background: Skin and soft tissue infections (SSTIs) are significant indications for antibiotic treatment. Daptomycin, a novel antibiotic, has been registered and licensed to be used in the treatment of these infections. However, its efficacy and safety remain controversial.

Objective: The objective of this study was to conduct a systematic review with trial sequential analysis (TSA) to evaluate the efficacy and safety of daptomycin for the treatment of SSTIs and to analyze whether the available sample size has been large enough and is conclusive.

Methods: PubMed, the Cochrane Library, and EMBASE were searched for published randomized controlled trials (RCTs) that compared daptomycin with other antibiotics in adult patients with SSTIs up to February 2016.

Results: This meta-analysis included eight randomized controlled trials $(n=2,002)$. There was no difference in either the clinical success rate (intention-to-treat population: relative risk $[\mathrm{RR}]=1.04,95 \%$ confidence interval $[\mathrm{CI}]=0.99-1.10, P=0.12$; clinically evaluable population: $\mathrm{RR}=1.00,95 \% \mathrm{CI}=0.97-1.04, P=0.82)$ or the microbiological success rate $(\mathrm{RR}=1.00,95 \%$ $\mathrm{CI}=0.95-1.06, P=0.92$ ) between the daptomycin and comparator groups for treating SSTIs, which was confirmed by TSA. Compared with vancomycin, daptomycin exhibited no advantage in increasing the clinical success rate $(\mathrm{RR}=1.03,95 \% \mathrm{CI}=0.95-1.13, P=0.47)$, and this was also confirmed by TSA. All-cause mortality, overall treatment-related adverse events, and creatine phosphokinase events were similar between these two groups.

Conclusion: Daptomycin and comparator drugs are equally efficacious with regard to clinical and microbiological success for patients with SSTIs, and TSA showed that no additional randomized controlled trials are required. Although daptomycin is a good alternative when other antibiotics are contraindicated for patients with SSTIs and it can serve as a first-line treatment for SSTIs, clinicians should be aware of potential adverse events, such as daptomycininduced acute eosinophilic pneumonia and creatine phosphokinase, when treating patients with daptomycin.

Keywords: daptomycin, skin and soft tissue infections, vancomycin, meta-analysis, trial sequential analysis

\section{Background}

Most skin and soft tissue infections (SSTIs) are caused by Staphylococcus aureus or $\beta$-haemolytic streptococci, ${ }^{1}$ and these are an important indication for antibiotic treatment. Vancomycin is the recommended standard therapy for the treatment of SSTIs when $\beta$-lactam antimicrobials cannot be used. ${ }^{2}$ However, with the increase of minimum inhibitory concentrations in methicillin-resistant $S$. aureus, the treatment for SSTIs becomes increasingly challenging. 
In recent years, a variety of novel antibiotics have been used for the treatment of SSTIs, ${ }^{1}$ and several meta-analyses ${ }^{3-6}$ have been conducted to evaluate the efficacy of novel antibiotics in the treatment of SSTIs. The use of linezolid, among these antibiotics, has resulted in better clinical and microbiological cure rates. ${ }^{2}$ However, its serious side effects that occur when the course of treatment exceeds 28 days, limit its clinical use. ${ }^{7}$ Further research is required to determine whether other drugs, including daptomycin, are more efficacious than the recommended standard therapy.

Daptomycin is a novel antimicrobial with in vitro bactericidal activity against most clinically relevant grampositive bacteria. It was first cleared by the US Food and Drug Administration in 2003 for the treatment of SSTIs in adults at a dose of $4 \mathrm{mg} / \mathrm{kg}$ once per day for 7-14 days. ${ }^{8,9}$ To date, $>70$ countries and regions have approved this drug for the treatment of SSTIs. Several meta-analyses ${ }^{6,10}$ have evaluated the effect of daptomycin in the treatment of SSTIs. However, no significant differences were found between daptomycin and standard drugs. Recently, two related randomized controlled trials (RCTs) ${ }^{11,12}$ were published. In the present study, the effect of daptomycin on the treatment of SSTIs was evaluated by conducting this meta-analysis with trial sequential analysis (TSA) to analyze whether the available sample size is large enough and conclusive.

\section{Methods}

The Preferred Reporting Items for Systematic Reviews and Meta-Analyses statement methodology was used to perform this meta-analysis. ${ }^{13}$

\section{Study selection}

PubMed, EMBASE, and the Cochrane Central Register of Controlled Trials were searched for relevant studies published up to February 2016. Search terms included "daptomycin," "cubicin," "lipopeptide," "skin infection," "soft tissue infection," "SSRIs," "cellulitis," "wounds infection," "abscess," "erysipelas," and "randomized controlled trial." Retrieval was limited to humans, and language was not restricted.

\section{Inclusion criteria}

The selection criteria were as follows: 1) population: patients with SSTIs; 2) intervention: antibiotics; 3) comparison: daptomycin and other antibiotics; 4) outcome measure: clinical or microbiological success; and 5) study design: RCT.

\section{Data extraction}

Two investigators (CL and ZM) conducted the data extraction independently using a standardized, premade form.
Differences between the data from these two investigators were resolved through discussion or by consulting a third investigator (FZ). The standard form included the following information: first author, study design, publication year, mean age of patients, number of patients, and antimicrobial agents and their doses. The primary outcome was clinical success, and analyses were conducted for both intention-totreat (ITT) and clinically evaluable (CE) groups of patients. Secondary outcomes were microbiological success, treatment-related adverse events, cases of elevated creatine phosphokinase (CPK), and all-cause mortality.

\section{Quality assessment}

The methodological quality of the included trials was assessed by two independent investigators (CL and ZM) according to the Cochrane Risk of Bias Tool. The standard criteria included the following domains: random sequence generation, allocation concealment, blinding of participants and personnel, blinding of outcome assessment, incomplete outcome data, selective reporting, and other biases. Each domain was classified as follows: "low risk," "unclear risk," or "high risk." Eligible trials that met the low risk of bias criteria for all the key domains were regarded as being at a low risk of bias, whereas those that met the high risk of bias criteria for all the key domains were regarded as being at a high risk of bias. All other trials were considered to have an unclear risk of bias.

\section{Grading quality of evidence}

The overall quality of the evidence of the outcomes was evaluated using Grading of Recommendations Assessment, Development, and Environment (GRADE). ${ }^{14}$ The grades of evidence were classified into four categories: 1) high: RCTs with no limitations and with consistent, precise, and directly applicable results without evidence of reporting bias; 2) moderate (downgraded one level from high): RCTs with important limitations; 3) low (downgraded two levels from high): RCTs with very serious limitations; and 4) very low (downgraded three levels from high): RCTs with very serious limitations and inconsistent results.

\section{Statistical analysis}

Review Manager Version 5.1.2 (RevMan; The Cochrane Collaboration, Oxford, UK) and Stata Version 12.0 (Stata Corporation, College Station, TX, USA) were used to conduct the data analyses. Pooled relative risks (RRs) with 95\% confidence intervals (CIs) for dichotomous outcomes were calculated by using both fixed effects and random effects models. Statistical heterogeneity between eligible trials was evaluated by using the $I^{2}$ test. $I^{2}>50 \%$ indicated significant 
heterogeneity among trials, ${ }^{15}$ and the random effects model was used to conduct the meta-analysis. The fixed effects analytical model was used to pool the results with acceptable or no heterogeneity. Sensitivity analyses were conducted to test the robustness of the results. Publication bias was assessed using the Begg test and the Egger test. All $P$-values were two-sided, and a $P$-value $<0.05$ indicated a statistically significant difference.

\section{Trial sequential analysis}

In meta-analyses, it is important to minimize the risk of reaching a false-positive or false-negative conclusion. However, repeated significance tests of sparse and accumulated data are prone to yielding random errors, which increase the risk of type I errors. ${ }^{16,17}$ In order to determine whether the evidence from a meta-analysis is reliable and conclusive, TSA should be used. This method assesses the risk of random errors and helps determine whether there is a need for additional trials. ${ }^{18}$ TSA was obtained with $\alpha=0.05$ (two-sided), $\beta=0.20$ (power $80 \%$ ), including the control event proportion observed in the comparator group or vancomycin group, and an RR reduction of $10 \%$ in outcomes. ${ }^{19}$ TSA was conducted using TSA Version 0.9 Beta (www.ctu.dk/tsa) ${ }^{20}$

\section{Results}

\section{Randomized trial characteristics}

A total of 233 potentially relevant studies and nine trials were retrieved for detailed assessment. One trial ${ }^{21}$ was excluded because it used a high dose of daptomycin $(10 \mathrm{mg} / \mathrm{kg})$. In total, eight studies ${ }^{11,12,22-27}$ were included in this meta-analysis (Figure 1). Table 1 summarizes the characteristics of all the included studies, which were published in English. These trials were published from 2004 to 2015. A total of 2,002 patients were included in this meta-analysis. All the included studies enrolled adult patients. The comparator drugs were vancomycin and semi-synthetic penicillin in two studies, ${ }^{22,27}$ vancomycin and teicoplanin in one study, ${ }^{25}$ vancomycin in four studies, ${ }^{11,12,24,26}$ and telavancin in one study. ${ }^{23}$

\section{Quality of studies}

Figure 2 shows the methodological quality assessments of the included trials. The allocation concealment was not clear. Because of the nature of the interventions, the studies were neither personnel-blinded nor participant-blinded. GRADE Working Group grades of evidence were moderate for the clinical and microbiological success rates and low for allcause mortality and adverse events.

\section{Primary outcome: clinical success rate on ITT and CE populations}

Seven trials ${ }^{11,12,22,23,25-27}$ reported the clinical success rate of daptomycin versus comparator drugs in ITT and CE populations. In the ITT population, the overall success rate was $72.5 \%(1,372 / 1,892)$. In the daptomycin group, $73.7 \%(705 / 957)$ of patients reached clinical success, compared with $70.9 \%(663 / 935)$ in the comparator group. There was no significant difference in the clinical success rate between the two groups $(\mathrm{RR}=1.04,95 \% \mathrm{CI}=0.99-1.10$, $P=0.12, I^{2}=0 \%$; Figure $3 \mathrm{~A}$ ). TSA was conducted by using fixed effects mode, and the cumulative $Z$-curve did not cross the conventional boundary for benefit but did cross the required information size (RIS) boundary (Figure 3C).

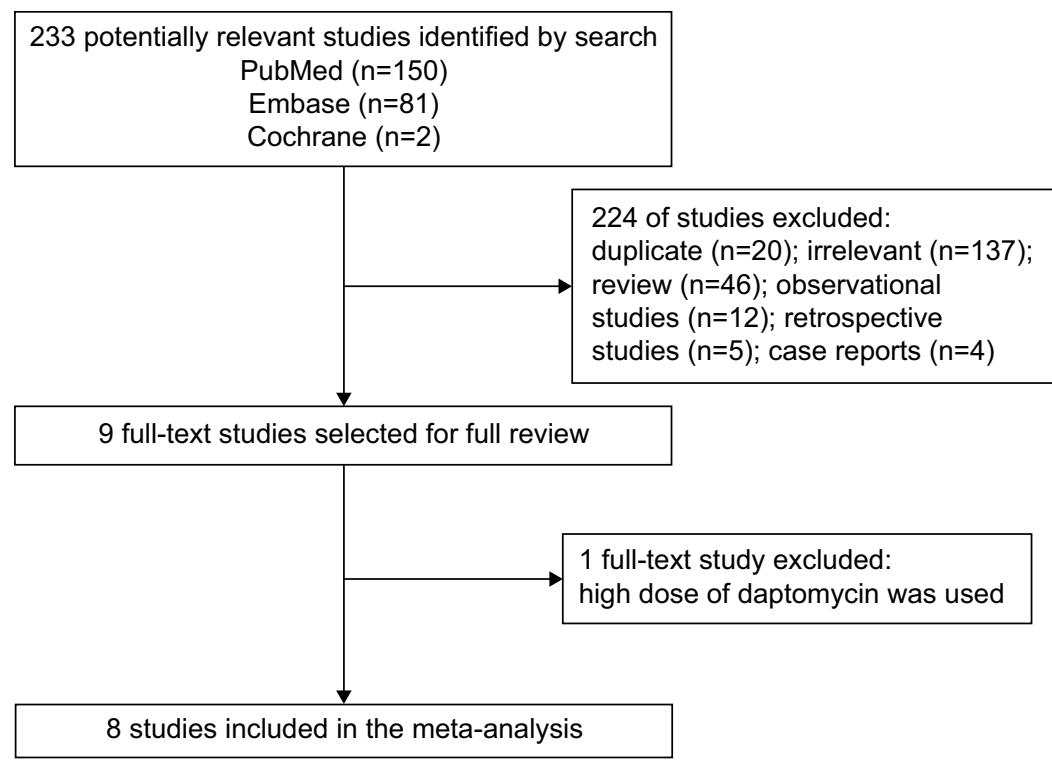

Figure I Flowchart of the study selection. 


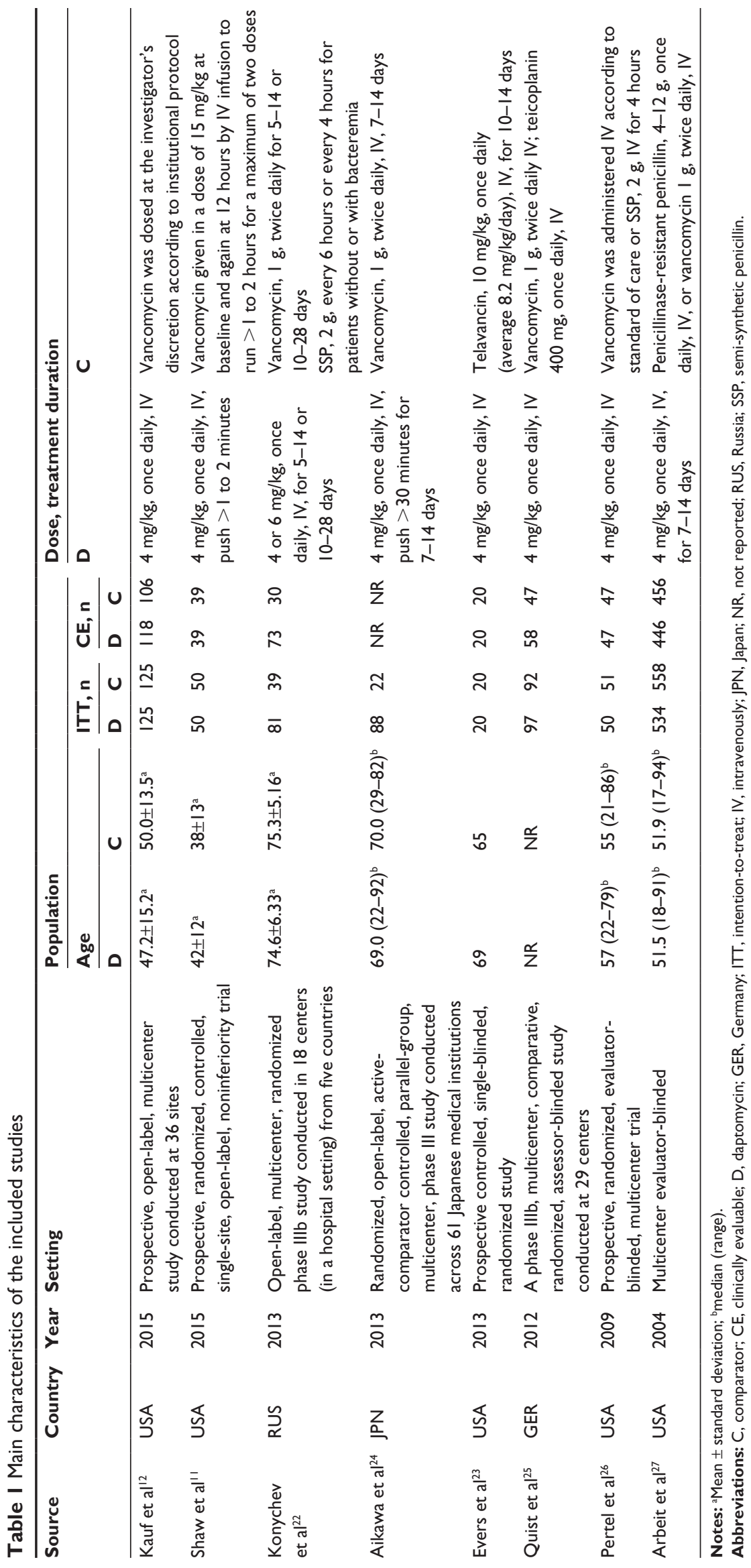




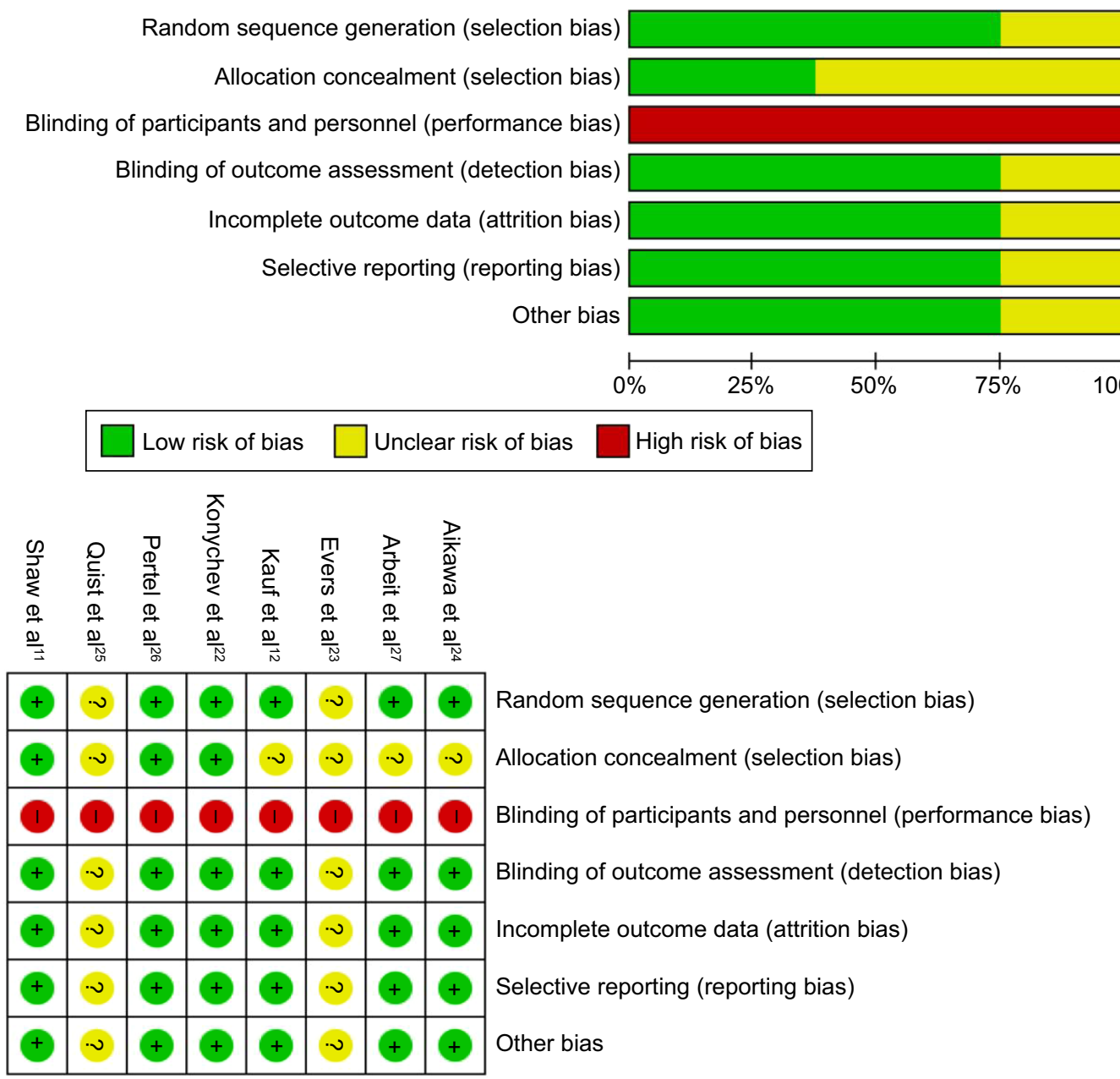

Figure 2 Assessment of the risk of bias.

Note: "+" indicates low risk of bias; "-" indicates high risk of bias; and "?" indicates unclear risk of bias.

These findings indicate that conclusive evidence was established, and further trials were not required. In the $\mathrm{CE}$ population, the overall success rate was $85.3 \%(1,319 / 1,546)$. In the daptomycin group, $85.6 \%(686 / 801)$ of patients reached clinical success, compared with $85.0 \%(633 / 745)$ in the comparator group. There was no significant difference in the clinical success rate between the two groups $(\mathrm{RR}=1.00$, $95 \% \mathrm{CI}=0.97-1.04, P=0.82, I^{2}=0 \%$; Figure $3 \mathrm{~B}$ ). TSA was conducted by using the fixed effects mode. The results were not renderable because the first information fraction exceeded $100 \%$ of the RIS boundary (Figure 3D). This result indicated that conclusive evidence was established and that further trials were not required. Six studies ${ }^{11,12,22,25-27}$ reported the clinical success rates of daptomycin and vancomycin in the CE population. As there was significant heterogeneity among studies $\left(\chi^{2}=23.25, d f=5, P=0.0003, I^{2}=78 \%\right.$; Figure $\left.4 \mathrm{~A}\right)$, a random effects model was used to conduct the meta-analysis, and the results showed no significant difference in the clinical success rate between the two groups $(R R=1.03$,
95\% CI $=0.95-1.13, P=0.47$; Figure $4 \mathrm{~A}$ ). In addition, the DerSimonian and Laird method for random effects analysis was also used to conduct TSA, and the cumulative $Z$-curve crossed the futility boundary, entered the futility area, and crossed the RIS boundary (Figure 4C). This result indicated that sufficient evidence was established and that further trials were not required.

\section{Sensitivity analysis}

Significant heterogeneity existed in the included studies between the daptomycin group and the vancomycin group $\left(I^{2}=78 \%\right)$, as shown in Figure 4A. After excluding the study conducted by Kauf et a $1^{12}$ there was no heterogeneity among the remaining studies $\left(I^{2}=0 \%\right)$, and there was no significant difference in the clinical success rate between the two groups $(\mathrm{RR}=1.07,95 \% \mathrm{CI}=0.98-1.16, P=0.12$; Figure 4B). The fixed effects model was used to conduct TSA, and the cumulative $Z$-curve did not enter the futility area and did not cross the conventional boundary (Figure 4D). 


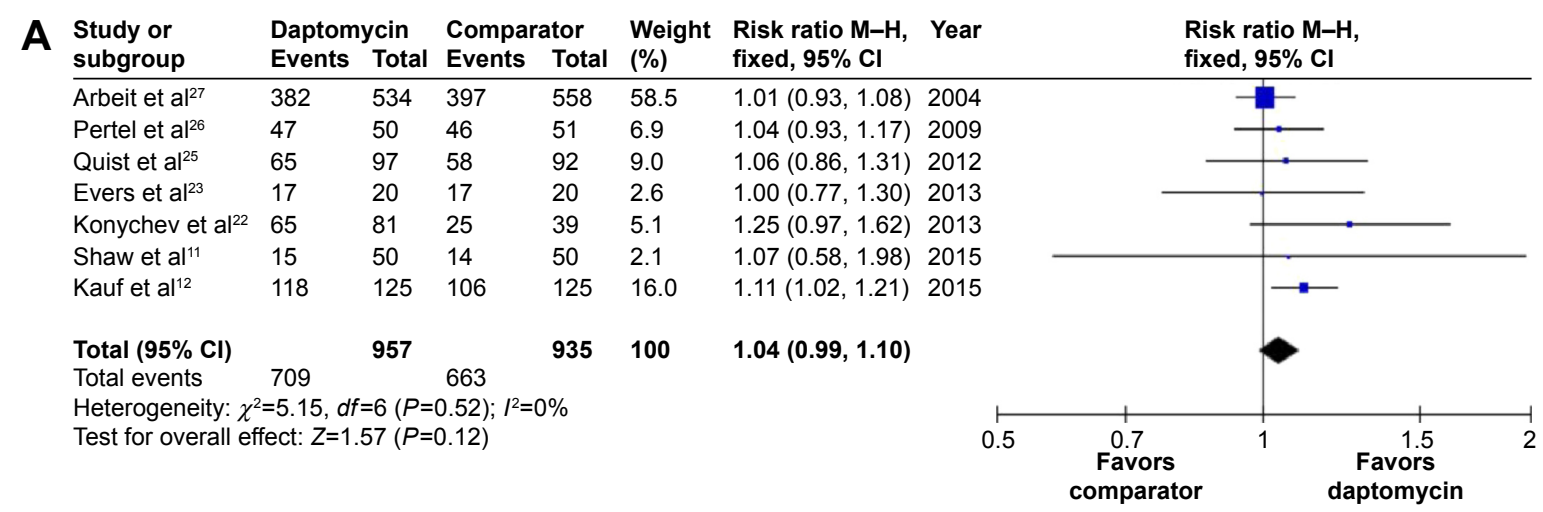

\begin{tabular}{|c|c|c|c|c|c|c|}
\hline $\begin{array}{l}\text { Study or } \\
\text { subgroup }\end{array}$ & $\begin{array}{l}\text { Daptom } \\
\text { Events }\end{array}$ & $\begin{array}{l}\text { ycin } \\
\text { Total }\end{array}$ & $\begin{array}{l}\text { Compar } \\
\text { Events }\end{array}$ & $\begin{array}{l}\text { ator } \\
\text { Total }\end{array}$ & $\begin{array}{l}\text { Weight } \\
\text { (\%) }\end{array}$ & $\begin{array}{l}\text { Risk ratio M-H, } \\
\text { fixed, } 95 \% \mathrm{Cl}\end{array}$ \\
\hline Arbeit et al27 & 372 & 446 & 384 & 456 & 58.4 & $0.99(0.94,1.05)$ \\
\hline Pertel et al ${ }^{26}$ & 47 & 47 & 46 & 47 & 7.2 & $1.02(0.96,1.08)$ \\
\hline Quist et al ${ }^{25}$ & 53 & 58 & 41 & 47 & 7.0 & $1.05(0.92,1.20)$ \\
\hline Konychev et al'22 & 65 & 73 & 25 & 30 & 5.5 & $1.07(0.89,1.28)$ \\
\hline Evers et $a^{23}$ & 17 & 20 & 17 & 20 & 2.6 & $1.00(0.77,1.30)$ \\
\hline Shaw et $\mathrm{al}^{11}$ & 15 & 39 & 14 & 39 & 2.2 & $1.07(0.60,1.91)$ \\
\hline Kauf et al ${ }^{12}$ & 118 & 118 & 106 & 106 & 17.3 & $1.00(0.98,1.02)$ \\
\hline Total $(95 \% \mathrm{Cl})$ & & 801 & & 745 & 100 & $1.00(0.97,1.04)$ \\
\hline $\begin{array}{l}\text { Total events } \\
\text { Heterogeneity: } \chi^{2} \\
\text { Test for overall ef }\end{array}$ & $\begin{array}{l}687 \\
=1.68, \\
\text { fect: } Z=\end{array}$ & $\begin{array}{l}=6(P=0 \\
23(P=0\end{array}$ & $\begin{array}{l}633 \\
.95) ; P^{2}=0 \\
.82)\end{array}$ & & & \\
\hline
\end{tabular}
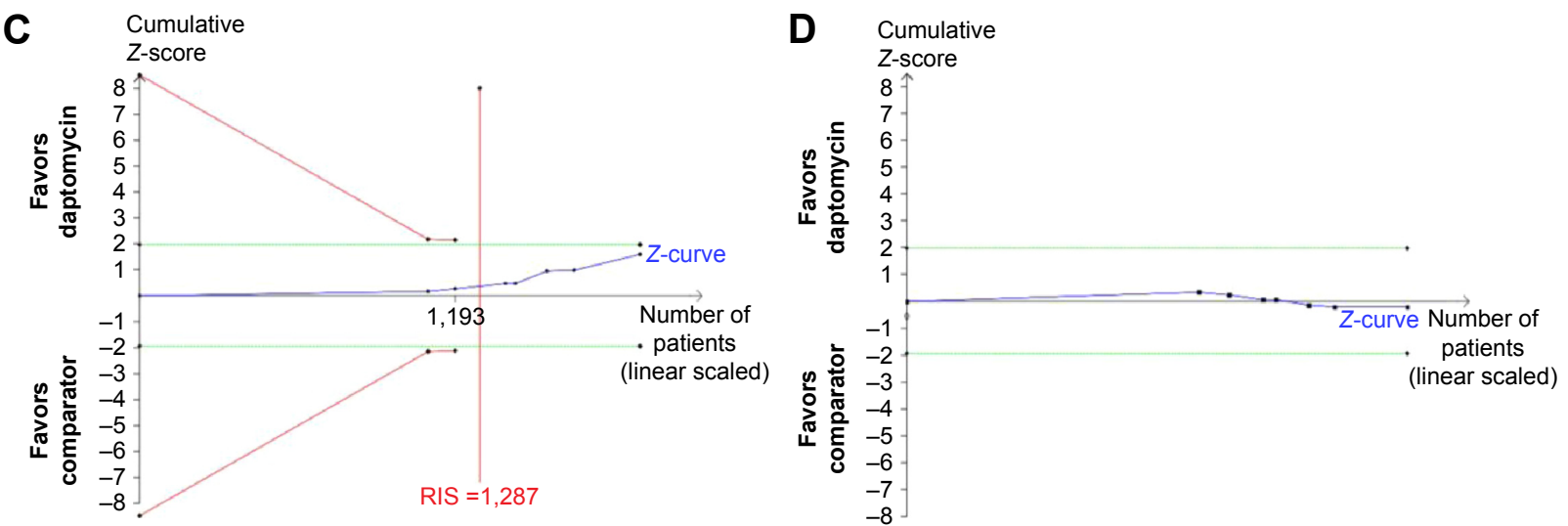

Figure 3 Effect of daptomycin versus other antibiotics on clinical success rate.

Notes: (A) Forest plot of clinical success rate (ITT population). (B) Forest plot of clinical success rate (CE population). (C) Fixed effects model of TSA for clinical success rate (ITT population). A diversity-adjusted information size of I,368 participants calculated on the basis of a clinical success rate of $71.0 \%$ in the comparator group, RRR $=10 \%$, $\alpha=5 \%$ (two-sided), $\beta=20 \%, R^{2}=0 \%$. A full blue cumulative $Z$-curve did not cross the conventional boundary for benefit but did cross the RIS boundary. (D) The fixed effects model of TSA for the clinical success rate (CE population). Because the first information fraction exceeded I00\% of RIS, the results were not renderable.

Abbreviations: $\mathrm{CE}$, clinically evaluable; $\mathrm{Cl}$, confidence interval; ITT, intention-to-treat; RIS, required information size; RRR, relative risk reduction; TSA, trial sequential analysis; $d f$, degree of freedom; $M-H$, Mantel-Haenszel.

\section{Secondary outcomes}

\section{Microbiological success rate}

Five studies ${ }^{22,24-27}$ reported the microbiological success rate, and no statistically significant difference was found between the daptomycin and comparator groups ( $R R=1.00$, $95 \%$ CI $=0.95-1.06, P=0.92, I^{2}=7 \%$; Figure $5 \mathrm{~A}$ ). In order to calculate the between-trial variance, the DerSimonian and Laird method for random effects analysis was used to conduct TSA, and the cumulative $Z$-curve did not cross the conventional boundary for benefit but did cross the RIS boundary (Figure 5B). Therefore, there was no statistically significant difference in the antimicrobial success rate between the two groups, indicating that sufficient evidence was established and that further trials were not required. In terms of the microbiological success rate for $S$. aureus infections, no significant difference was found between the two groups $\left(\mathrm{RR}=1.04,95 \% \mathrm{CI}=0.96-1.13, P=0.30, I^{2}=9 \%\right.$; Figure 6). For methicillin-resistant $S$. aureus infections, 


\begin{tabular}{|c|c|c|c|c|c|}
\hline \multirow{2}{*}{$\begin{array}{l}\text { A Study or } \\
\text { subgroup }\end{array}$} & \multicolumn{2}{|c|}{ Daptomycin } & \multicolumn{2}{|c|}{ Vancomycin } & \multirow{2}{*}{$\begin{array}{l}\text { Weight } \\
(\%)\end{array}$} \\
\hline & & & & & \\
\hline Arbeit et $\mathrm{al}^{27}$ & 90 & 111 & 127 & 172 & 18.6 \\
\hline Pertel et $\mathrm{al}^{26}$ & 47 & 47 & 46 & 47 & 27.0 \\
\hline Quist et al ${ }^{25}$ & 53 & 58 & 19 & 22 & 13.0 \\
\hline Konychev et al ${ }^{22}$ & 65 & 73 & 8 & 9 & 9.0 \\
\hline Kauf et al ${ }^{12}$ & 118 & 118 & 106 & 106 & 30.3 \\
\hline Shaw et al ${ }^{11}$ & 15 & 39 & 14 & 39 & 2.1 \\
\hline Total $(95 \% \mathrm{Cl})$ & & 446 & & 395 & 100 \\
\hline Total events & 388 & & 320 & & \\
\hline $\begin{array}{l}\text { Heterogeneity: } \tau^{2} \\
\text { Test for overall ef }\end{array}$ & $\begin{array}{l}=0.01 ; \chi^{2}= \\
\text { ect: } Z=0.7\end{array}$ & & & .00 & $I^{2}=78 \%$ \\
\hline
\end{tabular}

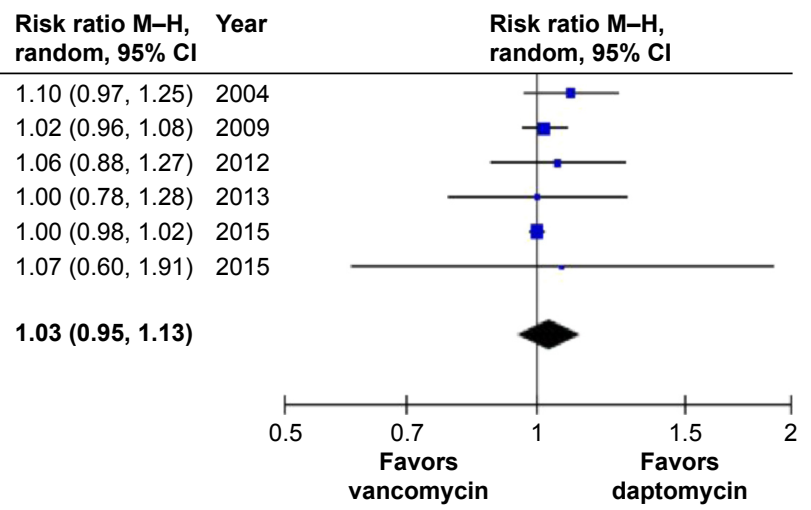

\begin{tabular}{|c|c|c|c|c|c|c|}
\hline $\begin{array}{l}\text { Study or } \\
\text { subgroup }\end{array}$ & $\begin{array}{l}\text { Daptom } \\
\text { Events }\end{array}$ & $\begin{array}{l}\text { ycin } \\
\text { Total }\end{array}$ & $\begin{array}{l}\text { Vancom } \\
\text { Events }\end{array}$ & $\begin{array}{l}\text { ycin } \\
\text { Total } \\
\end{array}$ & $\begin{array}{l}\text { Weight } \\
(\%)\end{array}$ & $\begin{array}{l}\text { Risk ratio } \mathrm{M}-\mathrm{H} \text {, } \\
\text { fixed, } 95 \% \mathrm{Cl}\end{array}$ \\
\hline Arbeit et $\mathrm{a}^{27}$ & 90 & 111 & 127 & 172 & 49.3 & $1.10(0.97,1.25)$ \\
\hline Pertel et al ${ }^{26}$ & 47 & 47 & 46 & 47 & 23.0 & $1.02(0.96,1.08)$ \\
\hline Quist et al ${ }^{25}$ & 53 & 58 & 19 & 22 & 13.6 & $1.06(0.88,1.27)$ \\
\hline Konychev et $\mathrm{al}^{22}$ & 65 & 73 & 8 & 9 & 7.1 & $1.00(0.78,1.28)$ \\
\hline Kauf et al ${ }^{12}$ & 118 & 118 & 106 & 106 & 0.0 & $1.00(0.98,1.02)$ \\
\hline Shaw et al ${ }^{11}$ & 15 & 39 & 14 & 39 & 6.9 & $1.07(0.60,1.91)$ \\
\hline Total $(95 \% \mathrm{Cl})$ & & 328 & & 289 & 100 & $1.07(0.98,1.16)$ \\
\hline $\begin{array}{l}\text { Total events } \\
\text { Heterogeneity: } \chi^{2} \\
\text { Test for overall ef }\end{array}$ & $\begin{aligned} & 270 \\
&= 2.54 \\
& \text { fect: } Z=\end{aligned}$ & $4(P=$ & $\begin{array}{l}214 \\
.64) ; I^{2} \\
.12)\end{array}$ & & & \\
\hline
\end{tabular}
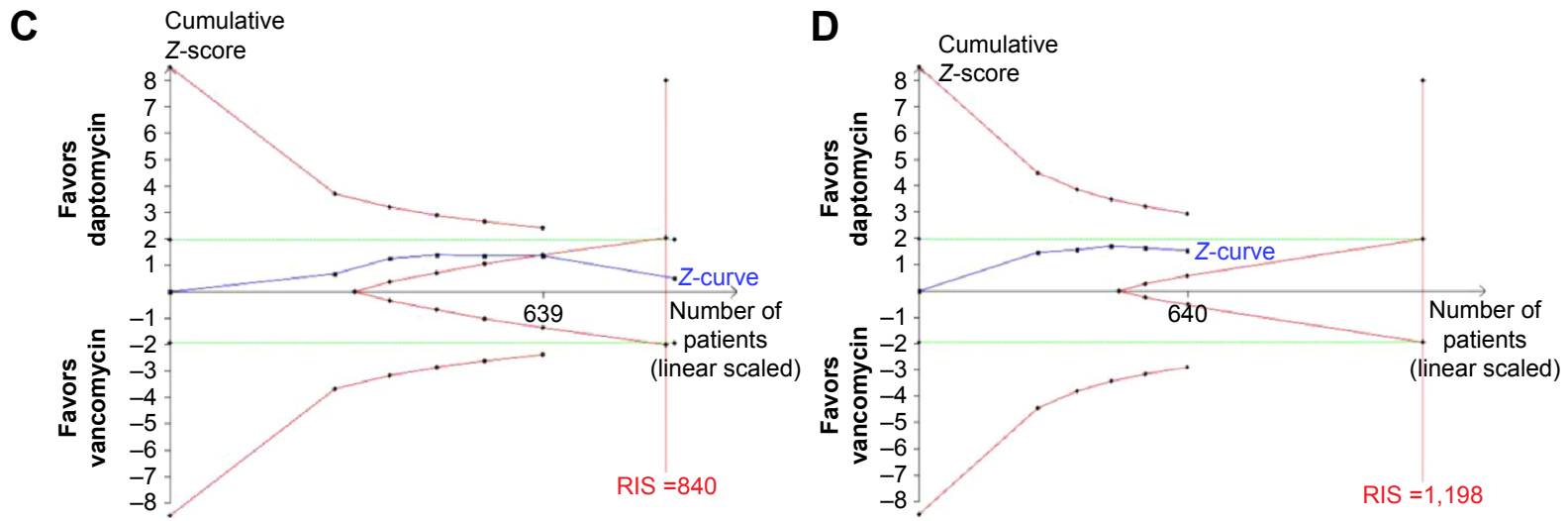

Figure 4 Effect of daptomycin versus vancomycin on clinical success rate.

Notes: (A) Forest plot of clinical success rate (CE population). (B) Forest plot of clinical success rate (CE population not including the study by Kauf et al). (C) Random effects model (DL method) of TSA for clinical success rate (CE population). A diversity-adjusted information size of 849 participants calculated on the basis of a clinical success rate of $81.0 \%$ in the vancomycin group, RRR $=10 \%, \alpha=5 \%$ (two-sided), $\beta=20 \%, P^{2}=78 \%$. A full blue cumulative $Z$-curve crossed the futility boundary and entered the futility area. (D) Fixed effects model of TSA for clinical success rate (CE population not including the study by Kauf et al). A diversity-adjusted information size of I, 198 participants calculated on the basis of a clinical success rate of $74.1 \%$ in the vancomycin group, $R R R=10 \%, \alpha=5 \%$ (two-sided), $\beta=20 \%, 12=0 \%$. A full blue cumulative $Z$-curve did not cross the conventional boundary for benefit and did not enter the futility area.

Abbreviations: $\mathrm{CE}$, clinically evaluable; Cl, confidence interval; DL, DerSimonian and Laird; RIS, required information size; RRR, relative risk reduction; TSA, trial sequential analysis; df, degree of freedom; $\mathrm{M}-\mathrm{H}$, Mantel-Haenszel.

the microbiological success rate did not differ significantly between the two groups ( $\mathrm{RR}=1.12,95 \% \mathrm{CI}=0.85-1.48$, $P=0.42, I^{2}=0 \%$; Figure 6 ). As only limited data were available, TSA was not conducted.

\section{All-cause mortality and adverse events}

All-cause mortality, overall treatment-related adverse events, and CPK events were similar between the daptomycin and comparator groups (Figure 6). As only limited data were available, TSA was not conducted.

\section{Publication bias}

The Egger's test provided no evidence of publication bias among the included trials for the clinical success rates ( $P=0.205$ for the ITT population and $P=0.117$ for the $\mathrm{CE}$ population) and the microbiological success rate $(P=0.275)$. 


\begin{tabular}{|c|c|c|c|c|c|c|}
\hline $\begin{array}{l}\text { Study or } \\
\text { subgroup }\end{array}$ & $\begin{array}{l}\text { Daptomyc } \\
\text { Events }\end{array}$ & in & $\begin{array}{l}\text { Compar } \\
\text { Events }\end{array}$ & $\begin{array}{l}\text { tor } \\
\text { Total } \\
\end{array}$ & $\begin{array}{l}\text { Weight } \\
(\%)\end{array}$ & $\begin{array}{l}\text { Risk ratio } \mathrm{M}-\mathrm{H} \text {, } \\
\text { fixed, } 95 \% \mathrm{Cl}\end{array}$ \\
\hline $\begin{array}{l}\text { Arbeit et al }{ }^{27} \\
\text { Pertel et al }{ }^{26}\end{array}$ & $\begin{array}{l}309 \\
16\end{array}$ & $\begin{array}{l}365 \\
22\end{array}$ & $\begin{array}{l}340 \\
7\end{array}$ & $\begin{array}{l}396 \\
14\end{array}$ & $\begin{array}{l}74.5 \\
2.0\end{array}$ & $\begin{array}{l}0.99(0.93,1.05) \\
1.45(0.81,2.61)\end{array}$ \\
\hline Quist et al25 & 56 & 57 & 39 & 43 & 10.2 & $1.08(0.98,1.20)$ \\
\hline Konychev et al ${ }^{22}$ & 54 & 65 & 23 & 27 & 7.4 & $0.98(0.81,1.18)$ \\
\hline Aikawa et al ${ }^{24}$ & 55 & 71 & 17 & 21 & 6.0 & $0.96(0.75,1.22)$ \\
\hline Total $(95 \% \mathrm{Cl})$ & & 580 & & 501 & 100 & $1.00(0.95,1.06)$ \\
\hline $\begin{array}{l}\text { Total events } \\
\text { Heterogeneity: } \chi^{2} \\
\text { Test for overall eff }\end{array}$ & $\begin{array}{l}490 \\
4.31, d f=4( \\
c t: Z=0.10(\end{array}$ & $P=0.9$ & $\begin{array}{l}426 \\
P^{2}=7 \%\end{array}$ & & & \\
\hline
\end{tabular}

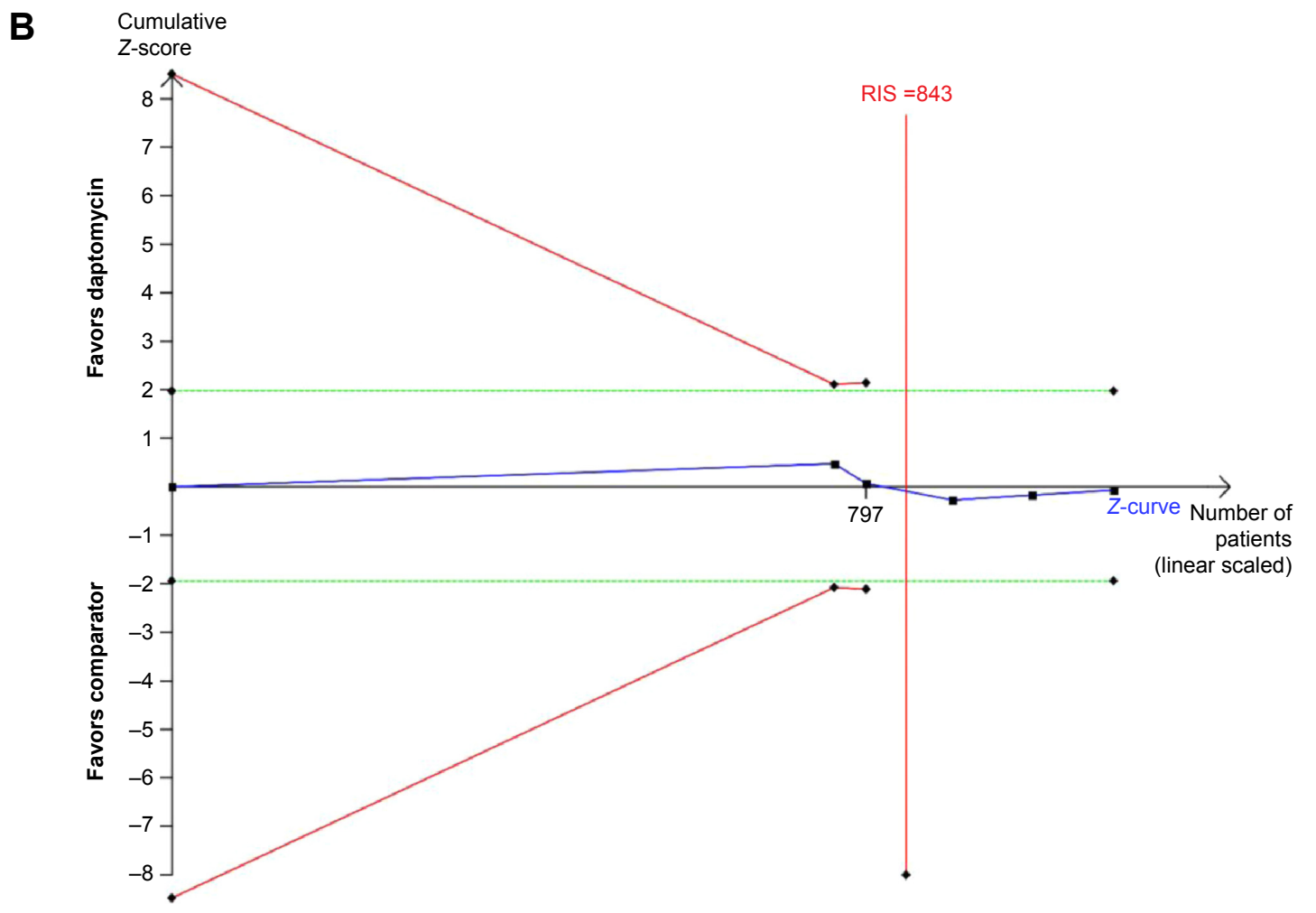

Figure 5 Effect of daptomycin versus other antibiotics on microbiological success rate based on the microbiologically evaluable population.

Notes: (A) Forest plot of microbiological success rate. (B) Fixed effects model of TSA for microbiological success rate. A diversity-adjusted information size of 843 participants calculated on the basis of a microbiological success rate of $85.0 \%$ in the comparator group, RRR $=10 \%, \alpha=5 \%$ (two-sided), $\beta=20 \%, P^{2}=0 \%$. A full blue cumulative $Z$-curve did not cross the conventional boundary for benefit but did cross the RIS boundary.

Abbreviations: $\mathrm{Cl}$, confidence interval; RIS, required information size; RRR, relative risk reduction; TSA, trial sequential analysis; $d f$, degree of freedom; $\mathrm{M}-\mathrm{H}$, MantelHaenszel.

\section{Discussion}

This systematic review of the currently available literature found that, (1) there were no significant differences in the clinical or microbiological success rate between the daptomycin and comparator groups, which was confirmed by TSA; (2) when compared with vancomycin, daptomycin did not have an advantage of improved clinical success, which was confirmed by TSA; (3) daptomycin and comparator drugs were equally efficacious in treating $S$. aureus or methicillin-resistant S. aureus infections, although TSA did not confirm these results; and (4) all-cause mortality, overall treatment-related adverse events, and CPK events were similar between the daptomycin group and the comparator or vancomycin group.
Some previous meta-analyses have been published on this topic, ${ }^{6,10}$ and the results have shown that the efficacy and safety of daptomycin in the treatment of SSTIs were similar to those of other antibiotics included in those meta-analyses. However, a conclusive result could not be found. Based on the cumulative evidence, the current meta-analysis was conducted by using TSA to provide more conservative estimates and to assess whether the available sample size has been large enough and is conclusive. In addition, GRADE Working Group criteria were used to assess the quality of evidence for outcomes, which helps physicians to make reliable clinical decisions.

The comparator group in this systematic review mainly included patients treated with vancomycin and those treated 
with teicoplanin, semi-synthetic penicillin, and telavancin. Vancomycin and teicoplanin are glycopeptide antibiotics and have been widely prescribed for several decades to treat resistant gram-positive infections, particularly SSTIs. However, vancomycin requires serum concentration monitoring, and some concerns regarding toxicity exist. ${ }^{28}$ Telavancin has in vitro activity against gram-positive pathogens and has been licensed to be used in the treatment of complicated SSTIs. However, telavancin is accompanied by more adverse events (including QT prolongation, elevated serum creatinine, and

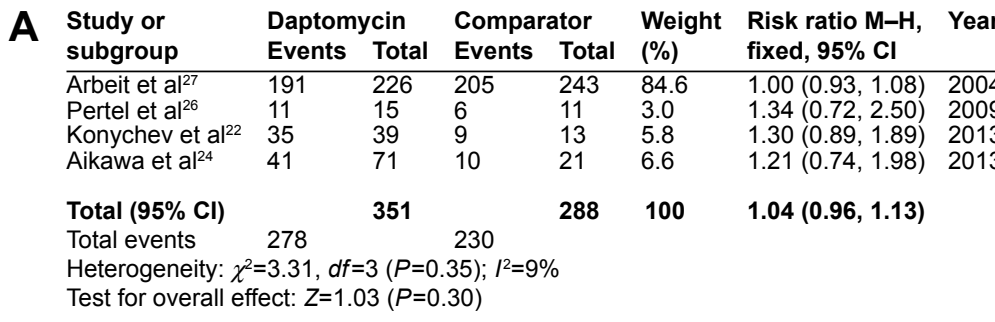

B Study or Daptomycin Comparator Weight Risk ratio $\mathbf{M}-\mathrm{H}$, Year \begin{tabular}{lllllllll} 
subgroup & Events & Total & Events & Total & (\%) & fixed, 95\% Cl & \\
\hline Arbeit et al ${ }^{27}$ & 21 & 28 & 25 & 36 & 62.1 & $1.08(0.80,1.46)$ & 2004
\end{tabular} $\begin{array}{llllllll}\text { Arbeit et } \mathrm{al}^{27} & 21 & 28 & 25 & 36 & 62.1 & 1.08(0.80,1.46) & 2004 \\ {\text { Aikawa et } \mathrm{al}^{24}}^{31} & 55 & 9 & 19 & 37.9 & 1.19(0.70,2.02) & 2013\end{array}$ Total $(95 \% \mathrm{Cl})$ Total events 83 55100

$1.12(0.85,1.48)$

Heterogeneity: $\chi^{2}=0.11, d f=1(P=0.74) ; l^{2}=0 \%$ Test for overall effect: $Z=0.81(P=0.42)$

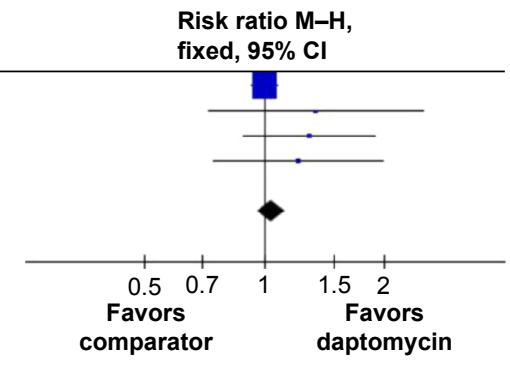

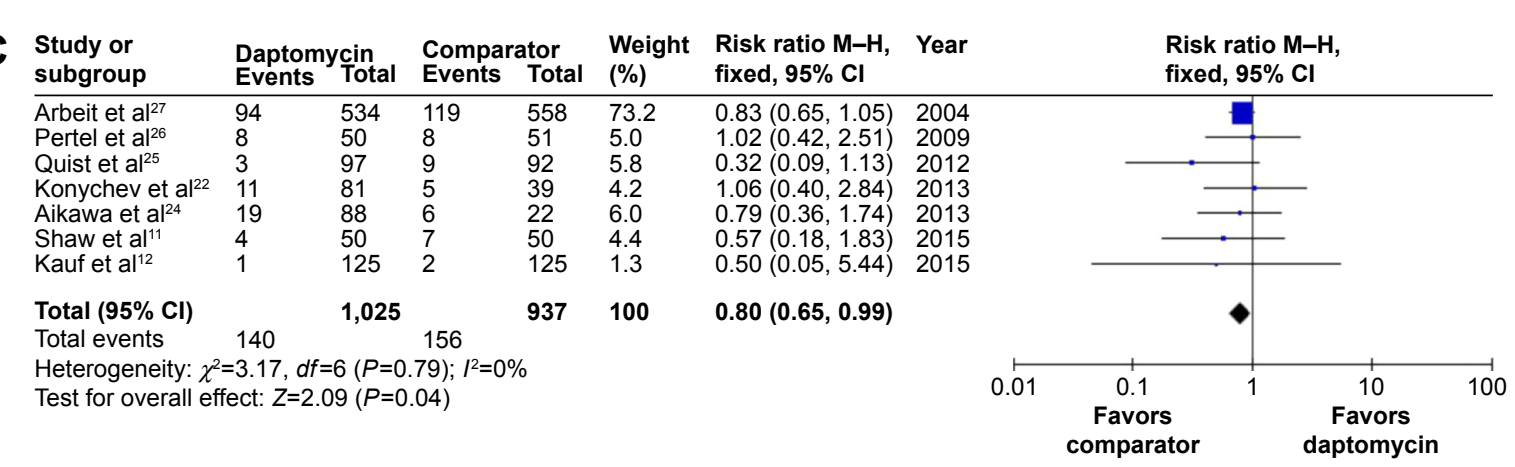

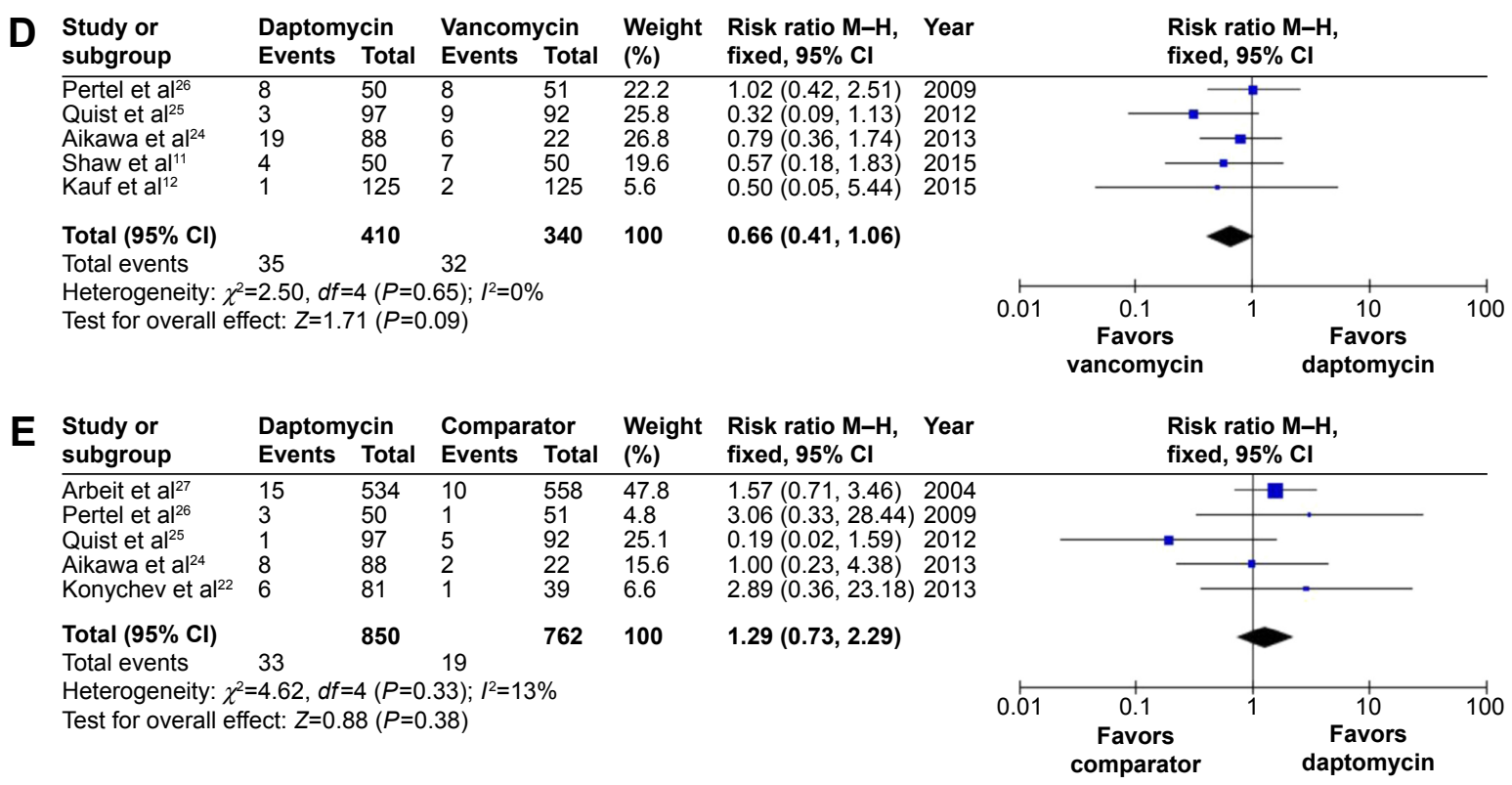

Figure 6 (Continued) 


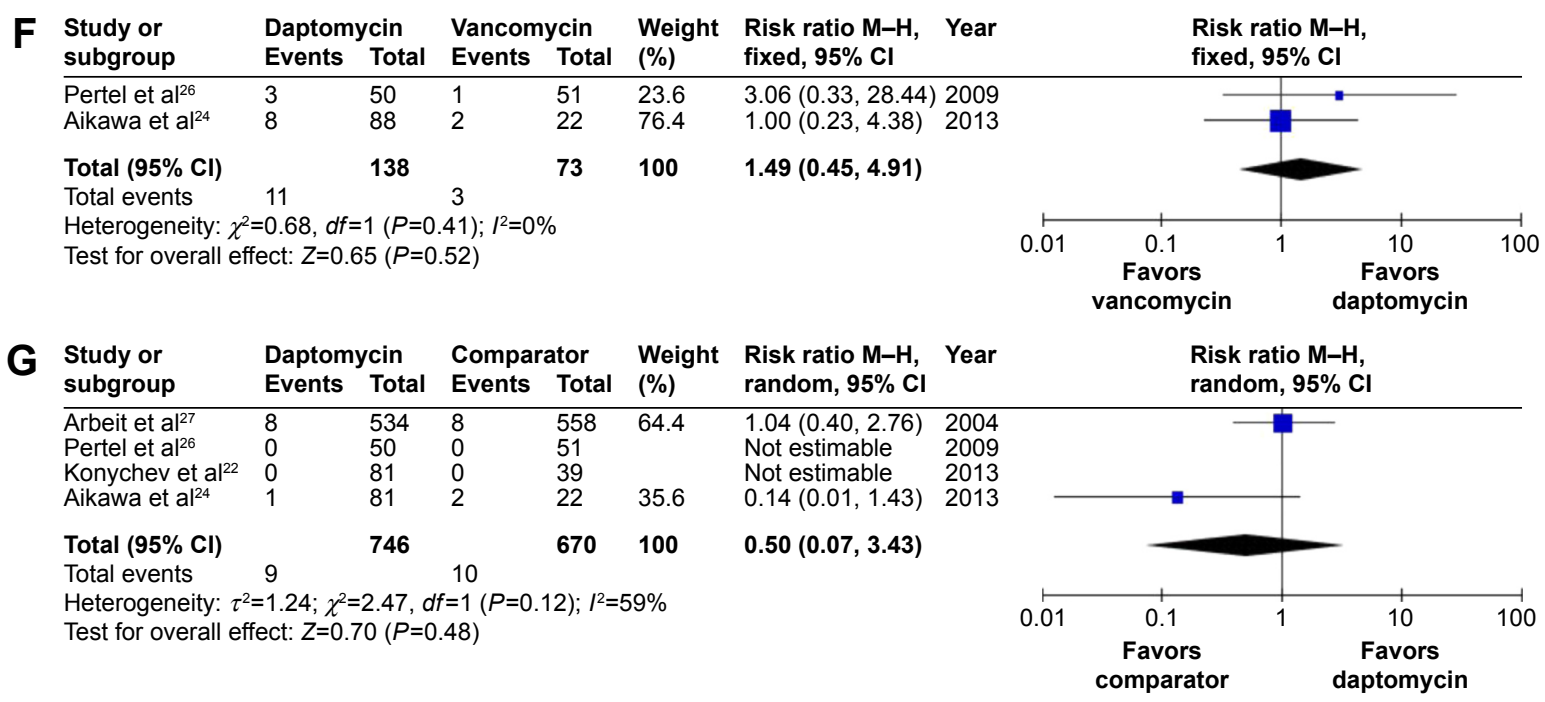

Figure 6 Forest plots of microbiological success rate (SA and MRSA), adverse events and all-cause mortality.

Notes: (A) Microbiological success rate for SA. (B) Microbiological success rate for MRSA. (C) Treatment-related adverse events (daptomycin vs comparator). The vertical line suggests no difference between daptomycin and the comparator drugs. (D) Treatment-related adverse events (daptomycin vs vancomycin). (E) Adverse events of CPK (daptomycin vs comparator). (F) Adverse events of CPK (daptomycin vs vancomycin). (G) All-cause mortality (daptomycin vs comparator).

Abbreviations: $\mathrm{Cl}$, confidence interval; CPK, creatine phosphokinase; MRSA, methicillin-resistant Staphylococcus aureus; SA, Staphylococcus aureus; df, degree of freedom; $\mathrm{M}-\mathrm{H}$, Mantel-Haenszel.

thrombocytopenia) $)^{29,30}$ than treatment with vancomycin, and the risk of death in patients with kidney problems or diabetes is substantially higher when treated with telavancin. ${ }^{31}$ Therefore, it should be used with caution. Daptomycin, which is a novel antibiotic for treating SSTIs, has bactericidal activity against $S$. aureus through the inhibition of DNA, RNA, and protein synthesis. ${ }^{32}$ However, because of an interaction between daptomycin and a pulmonary surfactant identified in vitro, ${ }^{33}$ daptomycin is not prescribed for the treatment of pneumonia. In addition, if new pulmonary infiltrates are observed in patients treated with daptomycin, ${ }^{34}$ these patients should be carefully watched for signs of daptomycin-induced acute eosinophilic pneumonia.

The present meta-analysis showed that the clinical and microbiological cure rates of daptomycin were not inferior to those of standard therapy for SSTIs, and this finding was confirmed by TSA. Therefore, daptomycin is a good alternative for patients with SSTIs when vancomycin is contraindicated. Further research should focus on other issues such as cost-efficiency, infection-related hospital length of stay, and whether the administration of daptomycin is convenient for outpatients.

Treatment-related adverse events were similar between both the groups. However, CPK is a special adverse event specific to daptomycin. Daptomycin binds to the skeletal muscle cell membranes, which can cause musculoskeletal injury and leakage of intracellular CPK from the myofibers through the modified membrane. ${ }^{35}$ Therefore, the CPK level should be closely monitored throughout the course of daptomycin therapy.

This systematic review has several limitations. First, due to the nature of the included studies, participant and personnel blinding was not performed, which may have resulted in performance and detection biases. Therefore, the GRADE approach was used to help physicians make reliable clinical decisions. Second, more than three classes of antibiotics were included in the comparator group; therefore, we compared daptomycin with vancomycin alone. Third, the study by Arbeit et $\mathrm{al}^{27}$ had a high weight in this meta-analysis, which may also have influenced the overall results. Fourth, patients' habits and health history have important effects on drug metabolism and drug choice (eg, smoking, diet, other drug usage, and liver and kidney failure), which might have created potential biases in this meta-analysis.

\section{Conclusion}

No significant differences were found in the clinical or microbiological success rate between daptomycin and the comparator drugs, and no additional RCTs are required to analyze these two aspects. The overall treatment-related adverse events and all-cause mortality were similar between daptomycin and the comparator drugs, and further research should focus on other issues such as cost-effectiveness, infection-related hospital length of stay, and whether the administration of daptomycin is convenient for outpatients. Although daptomycin is a good alternative when other antibiotics are contraindicated for 
patients with SSTIs and it can serve as a first-line treatment for SSTIs, clinicians should be aware of potential adverse events, such as daptomycin-induced acute eosinophilic pneumonia and CPK, when treating patients with daptomycin.

\section{Disclosure}

The authors report no conflicts of interest in this work.

\section{References}

1. Dryden MS. Alternative clinical indications for novel antibiotics licensed for skin and soft tissue infection? Curr Opin Infect Dis. 2015; 28(2):117-124.

2. O'Brien DJ, Gould IM. Does vancomycin have a future in the treatment of skin infections? Curr Opin Infect Dis. 2014;27(2):146-154.

3. An MM, Shen H, Zhang JD, Xu GT, Jiang YY. Linezolid versus vancomycin for meticillin-resistant Staphylococcus aureus infection: a meta-analysis of randomised controlled trials. Int J Antimicrob Agents. 2013;41(5):426-433.

4. He W, Zhang Y, Chen H, Zhao C, Wang H. Efficacy and safety of daptomycin for the treatment of infectious disease: a meta-analysis based on randomized controlled trials. J Antimicrob Chemother. 2014; 69(12):3181-3189.

5. Thom H, Thompson JC, Scott DA, Halfpenny N, Sulham K, Corey GR. Comparative efficacy of antibiotics for the treatment of acute bacterial skin and skin structure infections (ABSSSI): a systematic review and network meta-analysis. Curr Med Res Opin. 2015;31(8):1539-1551.

6. Wang SZ, Hu JT, Zhang C, et al. The safety and efficacy of daptomycin versus other antibiotics for skin and soft-tissue infections: a meta-analysis of randomised controlled trials. BMJ Open. 2014:4(6):e004744.

7. Yue J, Dong BR, Yang M, Chen X, Wu T, Liu GJ. Linezolid versus vancomycin for skin and soft tissue infections. Cochrane Database Syst Rev. 2014;7(1):CD008056.

8. Humphries RM, Pollett S, Sakoulas G. A current perspective on daptomycin for the clinical microbiologist. Clin Microbiol Rev. 2013; 26(4):759-780.

9. Silverman JA, Perlmutter NG, Shapiro HM. Correlation of daptomycin bactericidal activity and membrane depolarization in Staphylococcus aureus. Antimicrob Agents Chemother. 2003;47(8):2538-2544.

10. Bliziotis IA, Plessa E, Peppas G, Falagas ME. Daptomycin versus other antimicrobial agents for the treatment of skin and soft tissue infections: a meta-analysis. Ann Pharmacother. 2010;44(1):97-106.

11. Shaw GJ, Meunier JM, Korfhagen J, et al. Randomized controlled noninferiority trial comparing daptomycin to vancomycin for the treatment of complicated skin and skin structure infections in an observation unit. J Emerg Med. 2015;49(6):928-936.

12. Kauf TL, McKinnon P, Corey GR, et al. An open-label, pragmatic, randomized controlled clinical trial to evaluate the comparative effectiveness of daptomycin versus vancomycin for the treatment of complicated skin and skin structure infection. BMC Infect Dis. 2015; 15:503.

13. Moher D, Liberati A, Tetzlaff J, Altman DG. Preferred reporting items for systematic reviews and meta-analyses: The PRISMA Statement. Ann Intern Med. 2009;151(4):264-269.

14. Guyatt GH, Oxman AD, Schünemann HJ, Tugwell P, Knottnerus A. GRADE guidelines: a new series of articles in the journal of clinical epidemiology. J Clin Epidemiol. 2011;64(4):380-382.

15. Higgins JPT, Thompson SG, Deeks JJ, Altman DG. Measuring inconsistency in meta-analyses. BMJ. 2003;327(7414):557-560.

16. Brok J, Thorlund K, Gluud C, Wetterslev J. Trial sequential analysis reveals insufficient information size and potentially false positive results in many meta-analyses. J Clin Epidemiol. 2008;61(8):763-769.

17. Higgins JP, Whitehead A, Simmonds M. Sequential methods for random-effects meta-analysis. Stat Med. 2011;30(9):903-921.
18. Thorlund K, Devereaux PJ, Wetterslev J, et al. Can trial sequential monitoring boundaries reduce spurious inferences from meta-analyses? Int J Epidemiol. 2009;38(1):276-286.

19. Wetterslev J, Thorlund K, Brok J, Gluud C. Estimating required information size by quantifying diversity in random-effects model meta-analyses. BMC Med Res Methodol. 2009;9:86.

20. Thorlund K, Engstrom J, Wetterslev J, Brok J, Imberger G, Gluud C. User manual for trial sequential analysis (TSA). In Copenhagen Trial Unit, Centre for Clinical Intervention Research, Copenhagen, Denmark; 2011, p. 1-115. Available from: www.ctu.dk/tsa. Accessed April 20, 2015.

21. Katz DE, Lindfield KC, Steenbergen JN, et al. A pilot study of high-dose short duration daptomycin for the treatment of patients with complicated skin and skin structure infections caused by Gram-positive bacteria. Int J Clin Pract. 2008;62(9):1455-1464.

22. Konychev A, Heep M, Moritz RK, et al. Safety and efficacy of daptomycin as first-line treatment for complicated skin and soft tissue infections in elderly patients: an open-label, multicentre, randomized phase IIIb trial. Drugs Aging. 2013;30(10):829-836.

23. Evers R, Antony NL, Alozie O, Antony S. Pilot study comparing daptomycin and telavancin in the treatment of skin and soft tissue infections. Int $J$ Infect Dis. 2013;12(2):1-4.

24. Aikawa N, Kusachi S, Mikamo H, et al. Efficacy and safety of intravenous daptomycin in Japanese patients with skin and soft tissue infections. J Infect Chemother. 2013;19(3):447-455.

25. Quist SR, Fierlbeck G, Seaton RA, Loeffler J, Chaves RL. Comparative randomised clinical trial against glycopeptides supports the use of daptomycin as first-line treatment of complicated skin and soft-tissue infections. Int J Antimicrob Agents. 2012;39(1):90-91.

26. Pertel PE, Eisenstein BI, Link AS, et al. The efficacy and safety of daptomycin vs. vancomycin for the treatment of cellulitis and erysipelas. Int J Clin Pract. 2009;63(3):368-375.

27. Arbeit RD, Maki D, Tally FP, Campanaro E, Eisenstein BI; Daptomycin 98-01 and 99-01 Investigators. The safety and efficacy of daptomycin for the treatment of complicated skin and skin-structure infections. Clin Infect Dis. 2004;38(12):1673-1681.

28. Garau J, Ostermann H, Medina J, Avila M, McBride K, Blasi F. Current management of patients hospitalized with complicated skin and soft tissue infections across Europe (2010-2011): assessment of clinical practice patterns and real-life effectiveness of antibiotics from the REACH study. Clin Microbiol Infect. 2013;19(9):E377-E385.

29. Stryjewski ME, Lentnek A, O'Riordan W, et al. A randomized Phase 2 trial of telavancin versus standard therapy in patients with uncomplicated Staphylococcus aureus bacteremia: the ASSURE study. BMC Infect Dis. 2014;14:289.

30. Stryjewski ME, Graham DR, Wilson SE, et al. Telavancin versus vancomycin for the treatment of complicated skin and skin-structure infections caused by Gram-positive organisms. Clin Infect Dis. 2008; 46(11):1683-1693.

31. Torres A, Rubinstein E, Corey GR, Stryjewski ME, Barriere SL. Analysis of Phase 3 telavancin nosocomial pneumonia data excluding patients with severe renal impairment and acute renal failure. J Antimicrob Chemother. 2014;69(4):1119-1126.

32. Rybak MJ. The efficacy and safety of daptomycin: first in a new class of antibiotics for Gram-positive bacteria. Clin Microbiol Infect. 2006;12(Suppl 1):24-32.

33. Silverman JA, Mortin LI, Vanpraagh AD, Li T, Alder J. Inhibition of daptomycin by pulmonary surfactant: in vitro modeling and clinical impact. J Infect Dis. 2005;191(12):2149-2152.

34. Akcaer M, Karakas A, Tok D, Coskun O, Sari S. Eosinophilic pneumonia: daptomycin-induced lung complication. Med Mal Infect. 2016; 46(3):166-168.

35. Oleson FB Jr, Berman CL, Kirkpatrick JB, Regan KS, Lai JJ, Tally FP. Once-daily dosing in dogs optimizes daptomycin safety. Antimicrob Agents Chemother. 2000;44(11):2948-2953. 


\section{Publish your work in this journal}

Therapeutics and Clinical Risk Management is an international, peerreviewed journal of clinical therapeutics and risk management, focusing on concise rapid reporting of clinical studies in all therapeutic areas, outcomes, safety, and programs for the effective, safe, and sustained use of medicines. This journal is indexed on PubMed Central, CAS,

EMBase, Scopus and the Elsevier Bibliographic databases. The manuscript management system is completely online and includes a very quick and fair peer-review system, which is all easy to use. Visit http://www.dovepress.com/testimonials.php to read real quotes from published authors.

Submit your manuscript here: http://www.dovepress.com/therapeutics-and-clinical-risk-management-journal 